\title{
USO DA GEOPRÓPOLIS DA ESPÉCIE Melipona melanoventer NA MANUTENÇÃO DA QUALIDADE DO OVO
}

\author{
Juliana da Silva Galvão'; Graciene Conceição dos Santos²; Raul da Cunha Lima Neto². \\ ${ }^{1}$ Universidade Federal do Oeste do Pará, Santarém, Pará, Brasil, Julianagalvao07@gmail.com \\ 2 Universidade Federal do Oeste do Pará, Santarém, Pará, Brasil, gracienecsantos@yahoo.com.br \\ 2 Universidade Federal do Oeste do Pará, Santarém, Pará, Brasil, cunhalimant@gmail.com
}

RESUMO: Com o objetivo de avaliar a qualidade de ovos de galinha submetidos a tratamento superficial da casca utilizando solução de geoprópolis da espécie Melipona melanoventer, foi conduzido um experimento com 60 ovos postos no dia, armazenados por um período de 20 dias. O delineamento experimental foi inteiramente casualizado (DIC) em esquema fatorial $3 \times 4$ sendo três tratamentos (ovos não lavados, ovos lavados e ovos lavados e mergulhados em solução de geoprópolis a 10\%, avaliados em quatro tempos de armazenamento: 05, 10, 15 e 20 dias) com 05 repetições de um ovo cada. Foram analisados: peso do ovo; gravidade específica; altura da gema e unidade Haugh. Foi realizada análise de variância usando um modelo incluindo os efeitos do tempo de estocagem, do tratamento superficial da casca e da interação entre esses fatores. As médias do tratamento superficial da casca dos ovos ao longo do tempo de estocagem foram comparadas pelo teste Tukey a $5 \%$ de probabilidade. Para a maioria das características analisadas, foram observadas diferenças significativas $(P<0,05)$ entre os tratamentos e ao longo do tempo de estocagem. Com o aumento do tempo de estocagem, os ovos apresentaram redução na gravidade específica, altura de gema e Unidade Haugh, independente de terem recebido ou não tratamento superficial na casca. Concluiu-se que o tratamento superficial da casca de ovos com geoprópolis não é eficaz em manter a qualidade interna dos mesmos durante o tempo de armazenamento estudado.

PALAVRAS-CHAVE: Estocagem, Geoprópolis, Qualidade de ovos.

\section{USE OF THE Melipona melanoventer GEOPROPOLIS IN THE MAINTENANCE OF EGG QUALITY}

ABSTRACT: In order to evaluate the quality of hens eggs submitted to the surface treatment of the shell using a solution of Melipona melanoventer geopropolis, an experiment was conducted with 60 eggs placed on the day, stored for a period of 20 days. The experimental design was completely randomized (DIC) in a $3 \times 4$ factorial scheme, with three treatments (washed eggs, washed eggs and washed eggs and immersed in 10\% geopropolis solution (90\% ethanol plus 10\% geoprópolis) evaluated in four storage times: 05, 10, 15 and 20 days) with 05 replicates of one egg each. The 
following were analyzed: egg weight; specific gravity; height of yolk and Haugh unit. A variance analysis was performed using a model including the effects of storage time, bark surface treatment and interaction between these factors. The averages of the eggshell surface treatment over the storage time were compared using the Tukey test at $5 \%$ probability. For most of the analyzed characteristics, significant differences ( $P$ $<0.05)$ were observed between treatments and throughout the storage time. As the storage time increased, the eggs presented reduction in specific gravity, yolk height and independent Haugh Unit if they received or not surface treatment in the shell. It was concluded by means of this experiment that the surface coating of the eggshell with geopropolis is not effective in maintaining the internal quality of the same during the 20 days of storage.

KEYWORDS: Egg quality, Geopropolis, Storage.

\section{USO DEL Melipona melanoventer GEOPROPOLIS EN EL MANTENIMIENTO DE LA CALIDAD DEL HUEVO}

RESUMEN: Para evaluar la calidad de los huevos de gallina sometidos al tratamiento superficial de la cáscara usando una solución de Melipona melanoventer geopropolis, se realizó un experimento con 60 huevos colocados el día, almacenados por un período de 20 días. El diseño experimental fue completamente casualizado (DIC) en esquema factorial de $3 \times 4$, con tres tratamientos (huevos lavados, huevos lavados y huevos lavados e inmersos en solución de 10\% de geopropolis (90\% de etanol más 10\% de geoprópolis) evaluados en cuatro tiempos de almacenamiento: 05, 10, 15 y 20 días) con 05 repeticiones de un huevo cada una. Los siguientes fueron analizados: peso del huevo; gravedad específica; altura de la yema y de la unidad de Haugh. Un análisis de varianza se realizó utilizando un modelo incluyendo los efectos del tiempo de almacenamiento, el tratamiento de la superficie de la corteza y la interacción entre estos factores. Las medias del tratamiento de la superficie de la corteza del huevo a lo largo del tiempo de almacenaje se compararon usando la prueba de Tukey con una probabilidad del 5\%. Para la mayoría de las características analizadas, se observaron diferencias significativas $(P<0,05)$ entre los tratamientos ya lo largo del tiempo de almacenamiento. A medida que el tiempo de almacenamiento aumentó, los huevos presentaron reducción en la gravedad específica, altura de la yema y unidad Haugh independiente, si recibieron o no tratamiento superficial en la cáscara. Se concluyó por medio de esta experiencia que el revestimiento superficial de la cáscara de huevo con geopropolis no es efectivo en el mantenimiento de la calidad interna del mismo durante los 20 días de almacenamiento.

PALABRAS CLAVES: Calidad de los huevos, geoprópolis, almacenamiento. 
O ovo de galinha (Gallus domesticus) é um produto de grande aporte proteico/calórico e vitamínico, de baixo preço e fácil produção. O aumento do consumo de ovos e a utilização de suas vantagens nutricionais pela população dependem da qualidade do produto oferecido ao consumidor. O ovo começa a perder sua qualidade interna logo após a postura, caso não sejam tomadas medidas adequadas para sua conservação. A perda de qualidade é um processo inevitável e contínuo ao longo do tempo, mas que pode ser agravado por diversos fatores, alguns deles controláveis durante a póscolheita (BARBOSA et al., 2008).

Para que os nutrientes contidos no interior dos ovos não sejam transformados rapidamente em substâncias impróprias para a alimentação, faz-se necessário que os ovos sejam armazenados sob refrigeração, durante o período de comercialização, visto que desde o momento da postura até o consumo, podem haver períodos extensos de tempo que depreciam sua qualidade interna. Ovos embalados inadequadamente ou expostos a correntes de vento e a agentes contaminantes, e estocados sob temperatura elevada e baixa umidade têm alterações bioquímicas do albume mais aceleradas e estão mais propensos à contaminação por agentes patogênicos, reduzindo sua vida de prateleira (MOURA et al., 2008).

No momento da compra de ovos, o consumidor pode observar somente os aspectos externos e a data de validade. Já o conteúdo dos ovos deve ser garantido pelo produtor. Para que seja assegurada a qualidade interna dos ovos aos consumidores, deve-se regulamentar a avaliação microbiológica, físico-química e a refrigeração dos ovos, desde o processamento até a aquisição do produto (ALCÂNTARA, 2012).

Métodos de conservação e barreiras físicas vêm sendo pesquisados para minimizar a perda de qualidade durante $\quad$ armazenamento, possibilitando extensão da vida de prateleira (BHALE et al., 2003). 
O uso da própolis como um agente conservante tem sido uma alternativa considerada segura por parte dos consumidores, devido seu efeito antimicrobiano e sua utilização para a proteção de diversos produtos agrícolas durante o armazenamento COPUR et al., 2008; ÇANDIR et al., 2009; ÖZEDMIR et al., 2010). A própolis tem se mostrado um produto com alta capacidade inibidora de microrganismos sendo as bactérias Gram positivas, principalmente Staphylococcus, Streptococcus e leveduras Candida albicans (ALENCAR et al., 2007) mais sensíveis a ação da própolis. Assim como a própolis, a geoprópolis de abelhas sem ferrão tem se destacado por seus efeitos terapêuticos. Ações anti-inflamatória do extrato hidroalcoólico da geoprópolis de tiúba, provenientes do estado do Maranhão, foram demonstradas por Gomes (2005).

Carvalho (2009) em seu estudo sobre a influência da Própolis na vida de prateleira de ovos de galinha, concluiu que o tratamento de ovos de galinha com tintura de própolis aumenta sua vida de prateleira, uma vez que preserva suas características físicas e organolépticas por mais tempo. Além do aspecto técnico, aparentemente esta tecnologia mostra-se viável também quanto aos aspectos econômico, qualitativo e ecológico, uma vez que assegura uma alta qualidade, segurança e baixo custo.

Segundo Carvalho et al. (2007), o revestimento de ovos com própolis permite que a qualidade dos mesmos seja mantida em níveis adequados para o consumo por mais de 42 dias de armazenamento em temperatura ambiente, uma vez que mantém valores indicativos de boa qualidade para as variáveis unidade Haugh e massa específica, além de parâmetros microbiológicos compatíveis com a legislação vigente. $\bigcirc$ tratamento superficial da casca de ovos com solução de geoprópolis pode ser uma alternativa viável para aumentar o tempo de vida de prateleira dos ovos comerciais.

Este trabalho teve como objetivo avaliar a qualidade de ovos de galinha 
submetidos a tratamento superficial da casca utilizando solução de geoprópolis da espécie Melipona melanoventer.

O experimento foi realizado nas dependências do laboratório de TPOA da Universidade Federal do Pará (UFOPA), situada na cidade de Santarém-PA, com duração de 20 dias, no mês de Dezembro de 2016. Para o experimento, foram utilizados 60 ovos marrons postos no mesmo dia, por galinhas da linhagem COBB MX, oriundos de uma granja comercial na cidade de Santarém-PA.

O delineamento experimental utilizado foi o inteiramente casualizado (DIC) em esquema fatorial $3 \times 4$ sendo três tratamentos (ovos não lavados, ovos lavados e ovos lavados e mergulhados em solução de geoprópolis a 10\% (90\% de etanol mais 10\% de geoprópolis) avaliados em quatro tempos de armazenamento (05, 10, 15 e 20 dias) com 05 repetições de um ovo cada.

Dos 60 ovos, 20 ovos foram mantidos da mesma forma em que foram transportados da granja até 0 laboratório (ovos não lavados), os outros 40 ovos foram lavados em uma pia com água corrente, em seguida, foram colocados em uma bandeja para secar ao ar, após a secagem, foram divididos 20 ovos em bandejas de papelão para serem borrifados com a solução de geoprópolis a 10\% e os outros 20 ovos (somente lavados) para armazenagem.

As características analisadas foram: peso do ovo; gravidade específica; altura da gema e unidade Haugh.

No primeiro dia do experimento (dia zero), todos os ovos foram devidamente numerados com caneta permanente e pesados em balança analítica, com precisão de 0,0001g. Nos outros períodos de armazenamento $(05,10,15$ e 20 dias), novas pesagens foram realizadas. Foram escolhidos cinco ovos por tratamento seguindo a numeração.

A gravidade específica foi determinada pelo método da flutuação salina conforme metodologia descrita por Hamilton (1982). Para tal análise, foram utilizados sete baldes plásticos, um densímetro, água e sal comum. 
Foram feitas imersões dos ovos em soluções salinas com densidades que variavam de 1,060 até 1,090 g/ $\mathrm{cm}^{3}$ com intervalos de 0,005 $\mathrm{g} / \mathrm{cm}^{3}$. Os ovos foram colocados nos baldes com as soluções, da menor para a maior densidade e foram retirados ao flutuarem, sendo registrados os valores correspondentes às soluções dos recipientes. Antes de cada avaliação, as densidades foram conferidas com o auxílio do densímetro.

Para quantificar a altura de gema, a cada período, cinco ovos de cada tratamento, foram retirados aleatoriamente. Os ovos foram pesados individualmente, em balança analítica 0,0001g. Depois das pesagens dos ovos, os mesmos foram quebrados para realização das análises. Com o uso de um micrômetro no ponto central da gema, foi medido a altura da gema, em seguida a gema de cada ovo foi pesada e seu valor registrado.

Após serem pesados em balança semi-analítica, 5 ovos de cada tratamento foram quebrados e colocados numa superfície lisa de vidro, a altura do albume foi medida com um micrômetro no ponto médio entre a extremidade externa do albume mais espesso. A partir desses dados, a qualidade interna do ovo foi medida, pela unidade "Haugh", por meio da fórmula: $U H=100 * \log$ $(H+7,57-1,7 * W \quad 0,37)$ onde: $U H=$ Unidades Haugh; $H=$ Altura do Albúmen (mm); W = Peso do Ovo (g). Foi realizada análise de variância usando um modelo incluindo os efeitos do tempo de estocagem, do tratamento superficial da casca e da interação entre esses fatores. As médias do tratamento superficial da casca dos ovos ao longo do tempo de estocagem foram comparadas pelo teste Tukey a 5\% de probabilidade.

Os resultados referentes à Peso, Gravidade específica, Altura de gema e Unidade Haugh dos ovos de galinha, armazenados durante 20 dias em temperatura ambiente são apresentados na tabela 1. 
Tabela 1. Parâmetros de qualidade de ovos de galinha sem lavar, lavados e tratados superficialmente na casca com geoprópolis armazenados sob temperatura ambiente avaliados em diferentes períodos de estocagem.

\begin{tabular}{|c|c|c|c|c|c|}
\hline \multirow[b]{2}{*}{ Tratamento } & \multicolumn{5}{|c|}{ Tempo de estocagem } \\
\hline & 5 & 10 & 15 & 20 & Média \\
\hline \multicolumn{6}{|l|}{ Peso do ovo (\%) } \\
\hline Sem Lavar & $60,03 a A$ & $62,00 a A$ & $62,22 a A$ & $60,70 \mathrm{Aa}$ & 61,19 \\
\hline Lavados & $63,41 \mathrm{aA}$ & $63,00 \mathrm{aA}$ & $60,37 a A$ & $63,63 \mathrm{Aa}$ & 62,63 \\
\hline Geoprópolis & $61,49 a A$ & $60,37 a A$ & $60,32 \mathrm{aA}$ & $57,90 \mathrm{Aa}$ & 60,13 \\
\hline Média & $61,64 a$ & $61,81 a$ & $60,97 a$ & $60,95^{a}$ & \\
\hline \multicolumn{6}{|c|}{ Gravidade especifica } \\
\hline Sem Lavar & $1,073 a A$ & $1,067 \mathrm{abB}$ & $1,064 a b A$ & $1,061 \mathrm{Ba}$ & $1,066 \mathrm{AB}$ \\
\hline Lavados & $1,077 a A$ & $1,075 b A$ & $1,067 \mathrm{bcA}$ & 1,058Ca & $1,069 \mathrm{~A}$ \\
\hline Geoprópolis & $1,078 a A$ & $1,062 \mathrm{bB}$ & $1,061 \mathrm{bcA}$ & $1,052 \mathrm{Ca}$ & $1,064 \mathrm{~B}$ \\
\hline Média & $1,076 a$ & $1,068 b$ & $1,064 b$ & $1,057 c$ & \\
\hline \multicolumn{6}{|l|}{ Altura da gema } \\
\hline Sem Lavar & $17,36 \mathrm{bB}$ & 19,24abA & $20,45 a A$ & $20,00 \mathrm{Aa}$ & $19,26 \mathrm{~B}$ \\
\hline Lavados & $20,26 a A$ & $20,53 a A$ & $19,66 a A$ & $20,36 \mathrm{Aa}$ & $20,20 \mathrm{~A}$ \\
\hline Geoprópolis & $18,10 \mathrm{aB}$ & $16,56 a \mathrm{~B}$ & $16,84 \mathrm{aB}$ & $16,98 \mathrm{Ab}$ & $17,13 \mathrm{C}$ \\
\hline Média & $18,57 a$ & $18,74 a$ & $18,98 a$ & $19,27^{a}$ & \\
\hline \multicolumn{6}{|l|}{ Unidade Haugh } \\
\hline Sem Lavar & $92,15 a A$ & $90,65 a A$ & $87,03 \mathrm{aA}$ & $91,50 A a$ & $90,31 \mathrm{~A}$ \\
\hline Lavados & $97,69 a A$ & $93,61 a A$ & $89,13 a A$ & $87,58 \mathrm{Aa}$ & $92,00 \mathrm{~A}$ \\
\hline Geoprópolis & $81,15 \mathrm{aB}$ & $68,06 \mathrm{bB}$ & $75,00 \mathrm{abB}$ & $74,35 \mathrm{abB}$ & $74,65 \mathrm{~B}$ \\
\hline Média & $90,33 a$ & $83,64 a$ & $83,72 a$ & $85,20^{a}$ & \\
\hline
\end{tabular}

Médias seguidas por letras maiúsculas diferentes nas colunas diferem pelo teste de tukey $(P<0,05)$; Médias seguidas por letras minúsculas diferentes nas linhas diferem pelo teste de tukey $(P<0,05)$.

Para o parâmetro peso do ovo, nenhum dos tratamentos apresentou diferença significativa durante $\mathrm{O}$ período experimental. Silva et al. (2010) avaliando a estabilidade de ovos estocados em temperatura ambiente por quatro semanas com e sem revestimento de fécula de mandioca, observaram que tanto os ovos que receberam revestimento quanto os que não receberam não apresentaram alteração na perda de massa. Resultados semelhantes foram encontrados por Sfaciotte et al. (2014), mostrando que em 35 dias de estocagem o uso de óleo mineral na casca de ovos não influenciou o seu peso, assim como também não influenciou o peso dos ovos que não 
foram lavados, corroborando com os resultados encontrados nesse estudo.

Para a análise da gravidade específica, houve diferença entre as médias dos tratamentos. Os tratamentos lavados e com geoprópolis não diferiram estatisticamente do tratamento sem lavar, mas diferiram entre si, com média de gravidade maior para ovos lavados. Em se tratando do período de armazenamento, os três tratamentos (sem lavar, lavados e geoprópolis) não diferiram entre si no dia 05, dia 15 e nem no dia 20 de experimento. Somente no dia 10 houve diferença significativa, os ovos do tratamento lavados apresentaram maior gravidade específica, diferindo dos tratamentos sem lavar e com geoprópolis. Resultados semelhantes foram encontrados por Mendonça et. al. (2013), que ao avaliar a qualidade de ovos de codornas japonesas submetidos a tratamento superficial da casca armazenados em diferentes ambientes, com e sem refrigeração, por cinco semanas, verificaram que o peso específico reduziu ao longo do tempo de estocagem em temperatura ambiente, sendo que os ovos não submetidos a tratamento apresentaram menor peso específico, seguido da aplicação de própolis.

Os ovos do tratamento sem lavar apresentaram maior gravidade específica no dia 05 quando comparados aos ovos do dia 20, mas não diferiram dos demais tempos de armazenamento (dia 10 e 15).

Entre os ovos dos tratamentos lavados e com geoprópolis, houve uma redução gradativa da gravidade específica com o aumento do tempo de armazenamento, porém, entre os dias 10 e 15 não houve diferença significativa e os ovos do dia 15 não diferiram dos ovos do dia 20. Esses resultados podem ser explicados pelo fato de que com o aumento do tempo o ovo vai perdendo água e dióxido de carbono, através da casca. Dentro do ovo, existe entre a membrana do albume e a casca, a câmara de ar. Quanto mais fresco o ovo, menor ela é, pois quase nenhuma água saiu do seu interior. E a clara perde água através da casca, encolhendo-a, deixando mais 
espaço para a câmara de ar expandir, diminuindo então a densidade do ovo. Então a densidade do ovo fresco é maior do que a do ovo mais velho, pois estes últimos contêm maior volume ocupado por gás que baixa consideravelmente a densidade total.

De acordo com Mateos e Beorlegui (1991), em altas temperaturas durante o armazenamento, o ovo transpira, o que intensifica a perda de $\mathrm{CO}_{2}$ e água para o meio, tendo como consequência a perda de peso, aumento progressivo da câmara de ar e consequentemente, redução do peso específico. Este fenômeno se torna mais drástico para ovos armazenados sob temperatura não refrigerada e baixa umidade. Os resultados de gravidade específica encontrados neste estudo corroboram com o de Carvalho et al. (2013), os autores avaliaram o efeito da cobertura com própolis no aumento do prazo de validade de ovos de galinhas e verificaram que todos os tratamentos (sem lavar, lavados e com própolis) apresentaram reduções na densidade específica com o aumento dos dias de armazenamento.

Para o parâmetro altura de gema, os três tratamentos diferiram significativamente entre si, com maior média de altura de gema para os ovos do tratamento lavados.

No dia 5, os ovos do tratamento lavados apresentaram maior altura de gema e diferiu dos tratamentos sem lavar e com geoprópolis, no entanto, não houve diferença significativa entre ovos sem lavar e com geoprópolis.

Nos dias 10, 15 e 20, os ovos tratados com geoprópolis apresentaram altura de gema significativamente inferior quando comparados aos ovos sem lavar e lavados, que não diferiram entre si. Independentemente do tempo de armazenamento, o tratamento com ovos lavados foi o que apresentou maior altura de gema, seguido pelo tratamento sem lavar, e depois pelo tratamento com geoprópolis, que apresentou menor resultado para esse parâmetro.

Para análise de Unidade Haugh, houve diferença entre tratamentos, com o tratamento com geoprópolis 
apresentando menor Unidade Haugh comparado aos tratamentos sem lavar e lavados, que não diferiram estatisticamente entre si.

Os ovos não lavados e os lavados não apresentaram diferenças significativas de Unidade Haugh em nenhum dos períodos de armazenamento. Os ovos do tratamento com geoprópolis não apresentaram diferenças significativas no dia 05 quando comparados com os dias 15 e 20 de armazenamento, diferindo somente do dia 10, onde foi verificado uma queda brusca na Unidade Haugh.

A unidade Haugh é o parâmetro utilizado para expressar a qualidade do albúmen considerando a altura de albúmen e o peso do ovo, sua queda descreve a diminuição da qualidade do ovo durante o armazenamento (ALLEONI; ANTUNES, 2001).

A queda dos valores de $\mathrm{UH}$ (Unidade Haugh), pode ser relacionada com a diminuição do albume, possivelmente pelas perdas de água e dióxido de carbono (mais intensas quando em temperatura ambiente), que provoca a alteração do $\mathrm{pH}$, levando a gradual liquefação do albume, acentuando a diminuição do mesmo. $\bigcirc$ revestimento com geoprópolis não propiciou uma manutenção da qualidade interna esperada para os ovos avaliados.

A redução observada para a porcentagem de albúmen, ao longo do período de armazenamento, e aumento da altura de gema pode ser explicada pela passagem do albúmen fluido, por osmose, para a gema, determinando consequentemente, aumento do volume deste componente, levando ao enfraquecimento da membrana vitelínica (MORENG; AVENS, 1990).

Os resultados diferem dos resultados encontrados por Carvalho et. al. (2013) em estudo da extensão da vida de prateleira de ovos pela cobertura com própolis. Os autores mostraram que o valor da unidade de Haugh $(U H)$ diferiu significativamente entre tratamentos "com própolis" e os demais com o passar dos dias de armazenamento (42 dias), revelando melhores resultados de UH para os 
tratamentos com própolis. Diante dos

resultados de Carvalho et. al. (2013), os ovos tratados com própolis se mantiveram nas classificações AA e A (USDA, 2000), durante os 42 dias de armazenamento.

Tomando como base a classificação do Ministério da Agricultura dos Estados Unidos (USDA), a média de Unidade Haugh dos ovos deste trabalho, estão classificados em AA (100 até $72 \mathrm{UH})$, revelando excelente qualidade.

O revestimento superficial da casca de ovos de galinha com solução de geoprópolis não foi eficaz em manter a qualidade interna dos mesmos ao longo de 20 dias de armazenamento. Esse resultado pode ter sido influenciado por alguns fatores, tais como a possível volatização do álcool do extrato de geoprópolis ao longo do experimento ou mesmo as mudanças de temperaturas ocorridas ao decorrer dos dias.

\section{REFERÊNCIAS}

AHN, D. U.; KIM, S. K.; SHU, H. Effect of egg size and strain and age of hen on the solids contente of chicken eggs.
Poultry Science, Champaign, v. 76, p. 914-919, 1997.

AKBAR, M. K.; GAVORA, J. S.; FRIARS, G. W.; GOWE, R. S. Composition of eggs by comercial size categories: effects of genetic group, age, and diet. Poultry Science, Champaign, v. 62, p. 925-933, 1983.

ALCÂNTARA, J.B. Qualidade físicoquímica de ovos comerciais: Avaliação e manutenção da qualidade. Programa de pós-graduação em Ciência Animal - UFG. Goiânia, 2012.

ALENCAR, S. M.; OLDONI, T.L.C.; CASTRO, M.L; CABRAL, I.S.R.; COSTANETO, C.M.; CURY, J. A.; ROSALECN, P. L.; IKEGAKI, M. Chemical composition and biological activity of a new type of Braxillian propolis: Red propolis. Journal of Ethnopharmacology. v.113, p. 278-283, 2007.

ALENCAR, S.M.; OLDONI, T.L.C.; CASTRO, M.L.; CABRAL, I.S.R.; COSTANETO, C.M.; CURY, J.A.; ROSALEN, P.L.; IKEGAKI, M. Chemical composition and biological activity of a new type of Brazilian propolis: Red propolis. Journal of Ethnopharmacology, v. 113, n. 2, p. 278-283, 2007.

AlLeONI, A. C. C.; ANTUNES, A. J. Unidade Haugh como medida da qualidade de ovos de galinha armazenados sob refrigeração. Scientia Agricola, Piracicaba, v. 58, n. 4, p. 681685, 2001.

ANDRADE, A. N. Effects of high environmental temperature and diets on egg shell quality andperformance of laying hens. 1975. 114 f. Dissertação 
("Doctor of Philosophy") PurdueUniversity, Maryland, U.S.A. 1975.

AYGUN, A; SERT, D.; COPUR, G. Effects of propolis on eggshell microbial activity, hatchability, and chick performance in Japanese quail (Coturnix coturnix japonica) eggs. Poultry Science, v. 91, p.1018-1025, 2012.

BAIÃO, N. C; CANSADO, S. V. Fatores que afetam a qualidade da casca do ovo. Caderno Técnico da Escola de Veterinária UFMG, Belo Horizonte, n.21, p. 43-59, 1997.

BAPTISTA, R.F. Avaliação da qualidade interna de ovos de codorna (Coturnix coturnix japônica) em função da variação da temperatura de armazenamento. 2002. 95p. Dissertação (Mestrado em Medicina Veterinária) - Universidade Federal Fluminense, Niterói.

BARBOSA, N. A. A.; SAKOMURA, N. K.; MENDONÇA, M. O.; FREITAS, E. R.; FERNANDES, BHALE， S.; NO, H.K.; PRINYAWIWATKUL, W.; FAAR, A.J.; NADARAJAH, K.; MEYERS, S.P. Chitosan cooating improves shell life of eggs. Journal Food Sciences, v. 68, p. 2378-2383, 2003.

BARBOSA, N. A. A.; SAKOMURA, N. K.; MENDONÇA, M. O.; FREITAS, E. R. FERNANDES, J. B. K. Qualidade de ovos comerciais provenientes de poedeiras comerciais armazenados sob diferentes tempos e condições de ambientes. ARS Veterinária, v. 24, n. 2, p. 127-133, 2008.
BHALE, $\quad S_{. ;} \quad N O, \quad H . \quad K_{.} ;$ PRINYAWIWATKUL, W.; FARR, A. J.; NADARAJAH, K.; MEYERS, S. P. Chitosan coating improves shelf life of eggs. Journal of Food Science, Chicago, v. 68, n. 7, p. 2378-2383, sept. 2003.

BHALE, $\quad S_{. ;} \quad$ NO, $\quad$ H.K.; PRINYAWIWATKUL, W.; FAAR, A.J.; NADARAJAH, K.; MEYERS, S.P. Chitosan cooating improves shell life of eggs. Journal Food Sciences, v. 68, p. 2378-2383, 2003.

ÇANDIR, E.E.; ÖZDEMIR, A.E.; SOYLU, E.M.; SAHINLER, N.; GÜL, A. Effects of propolis on storage of sweet cherry cultivar Aksehir Napolyon. Asian Journal of Chemistry, v. 21, n. 4, p. 2659-2666, 2009.

CANER, C. Whey protein isolate coating and concentration effects on egg shelf life. Journal of the Science of Food and Agriculture, New York, v. 85, n. 13, p. 2143-2148, 2005.

CARVALHO, F.B.C.; STRINGHINI, J.H.; JARDIM FILHO, E.M. Qualidade interna e da casca para ovos de poedeiras comerciais de diferentes linhagens e idades. Ciência Animal Brasileira, v. 8, p. 25-29, 2007.

CARVALHO, J.X. Influência da própolis na vida de prateleira de ovos de galinha. Revista Brasileira de Agroecologia, v.4, n. 2, p.718-720, 2009.

CARVALHO, J.X.; SUÁREZ, R.O.; MENDES, F.Q.; FERNANDES, R.V.B.; CUNHA, M.C.; CARVALHO, A.M.X. Extensão da vida de prateleira de ovos 
pela cobertura com própolis. Semina:

Ciências Agrárias, v. 34, n. 5, p. 22872296, 2013.

COPUR, G.; CAMCI, O.; SAHINLER, N.; GUL, $A$. The effect of propolis egg shell coatings on interior egg quality. Archive Fur Geflugelkunde, v. 72, n.1, p. 35-40, 2008.

COTTA, T. Reprodução da galinha e produção de ovos. Lavras: UFLAFAEPE, 1997. p. 81-92.

CUNHA, I. B. S.; SAWAYA, A. C. H. F.; CAETANO, F. M.; SHIMIZU, M. T. ;MARCUCCI, M.C.; DREZZA, F. T.; POVIA, G. S.; CARVALHO, P. O. Factors that influence the yield and composition of Brazillian propolis extracts. Journal of the Brazillian Chemical Society, v. 15, p. 964-970, 2004.

DUALIBE, S.A.C.; GONÇALVES, A.G.; AHID, F. J. M. Effect of a propolis extract on Streptococcus mutans counts in vivo. Journal of Applied Oral Science, v. 15, p. 420-423. 2007.

DUTRA-DE-OLIVEIRA, J. E.; MARCHINI, J. S. Ciências nutricionais. $2^{a}$ Edição. São Paulo: Sarvier, 2008. 747p.

FIANCO, A.L.B.; FALCÃO, M.; CASSEL, E.; MILÃO, D. Determinação da atividade antimicrobiana e teor de polifenóis totais de extratos etanólicos de própolis das abelhas sem ferrão Tetragonisca angustula (Jataí) e Scaptotrigona bipunctata (Tubuna). Revista Liberato, v. 14, n. 21, p. 1-112, jan./jun. 2013.
FIGUEIREDO, T. C.; CANCADO, S. V.; VIEGAS, R. P.; REGO, I. O. P.; LARA, L. J. C; SOUZA, M. R.; BAIAO, N. C. Qualidade de ovos comerciais submetidos a diferentes condições de armazenamento. Arquivo Brasileiro de Medicina Veterinária e Zootecnia, v. 63, n. 3, p. 712-720, 2011.

FRANCHIN, M.; CUNHA, M. G.; DENNY, C.; NAPIMOGA, M. H.; CUNHA, T. M.; KOO, H.; DE ALENCAR, S. M.; IKEGAKI, M.; ROSALEN, P. L. Geopropolis from Melipona scutellaris decreases the mechanical inflammatory hypernociception by inhibiting the production of IL-1 $\beta$ and TNF- $\alpha$ Journal of Ethnopharmacology, v. 143, n. 2, p. 709-15, 2012.

GOMES, V. A. Estudo da atividade farmacológica do extrato hidroalcoólico de geoprópolis de tiúba. 48f. Monografia (Graduação em Farmácia) - Universidade Federal do Maranhão, São Luís, 2005.

HAMILTON, R. G. M. Methods and factors that affect the measurement of egg shell quality. Poultry Science. v. 61, n. 10, p. 2022-2039, 1982.

HAWTHORN, J. Fundamentos de Ciência de los Alimentos. Zaragoza: Acribia, 1983, p.114-122.

J. B. K. Qualidade de ovos comerciais provenientes de poedeiras comerciais armazenados sob diferentes tempos e condições de ambientes. ARS Veterinaria, Jaboticabal, v. 24, n. 2, p. 127-133, 2008.

JIRANGRAT, W.; TORRICO, D. D.; NO, J.; NO, H. K.; PRINYAWIWATKUL, W. 
Effects of mineral oil coating on internal quality of chicken eggs under refrigerated storage. International Journal of Food Science \& Technology, v. 45, p. 490-495, 2010.

JONES, D. R.; THARRINGTON, J. B.; CURTIS, P. A.; ANDERSON, K. E.; KEENER, K. M.; JONES, F. T. Effects of cryogenic cooling of shell eggs on egg quality. Poultry Science, v. 81, n. 5, p. 727-733, 2002.

KERR, W. E. Abelhas indígenas brasileiras (meliponíneos) na polinização e na produção de mel, pólen, geoprópolis e cera. Informe Agropecuário, v. 13, n. 149, p. 15-22, 1987.

LIBERIO, S.; PEREIRA, A. L. A.; DUTRA, R. P.; REIS, A. S.; ARAÚJO, M. J. A. M.; MATTAR, N. S.; SILVA, L. A.; RIBEIRO, M. N. S.; NASCIMENTO, F. R.; GUERRA, R. N. M.; MONTEIRO-NETO, V. Antimicrobial activity against oral pathogens and immunomodulatory effects and toxicity of geopropolis produced by the stingless bee Melipona fasciculata Smith. BMC Complementary and Alternative Medicine, v. 11, n. 108, p. 1-10, 2011.

LIMA, L. G. Influência da temperatura, período de armazenamento e da cor da casca na qualidade interna e externa de ovos de poedeiras comerciais. Rio Largo, 2012. 69 p. Dissertação (Mestrado em Zootecnia) Universidade Federal de Alagoas.

MAGALHÃES, A. P. C. Qualidade de Ovos Comerciais de Acordo com a Integridade da Casca, Tipo de Embalagem e Tempo de
Armazenamento. 2007. 43 p. Dissertação (Mestrado em Zootecnia) Universidade Federal Rural do Rio de Janeiro.

MATEOS, G. G.; BEORLEGUI, C. B Nutricion y alimentacion de gallinas ponedoras. Madrid: Mundi-Prensa, 1991. 263p.

MELLOR, D. B.; GARDPMER, F. A.; CAMPOS, E. J. Effect of tipe of package and storage temperature on interior quality of shell treated shell eggs. Poultry Science, Champaign, v. 54, n. 3, p. 742-746, 1975.

MENDONÇA, M. O.; REIS, R. S.; BARRETO, S. L. T.; MUNIZ, J. C. L.; VIANA, G. S.; MENCALHA, R.; FERREIRA, R. C.; RIBEIRO, C. L. N. Qualidade de ovos de codorna submetidos ou não a tratamento superficial da casca armazenado em diferentes ambientes. Revista Brasileira Saúde Produção Animal, v. 14, n. 1, 2013.

MILES, R. D. Gravedad específica del huevo-establecimento de un programa de verificación. Generalidades sobre la calidad del cascarón de huevo. México: Associación Americana de Soya, 1993. p. 1-8.

MORENG, R. E.; AVENS, J. S. Ciência e produção de aves. São Paulo: Roca, 1990.

MOURA, A. M. A.; OLIVEIRA, N. T. E.; THIEBAUT, T. L.; MELO, T. V. Efeito da temperatura de estocagem e do tipo de embalagem sobre a qualidade interna de ovos de codornas japonesas 
(Coturnix japonica). Ciência e Agrotecnologia, Lavras, v. 32, n. 2, p. 578-583, mar./abr., 2008.

MURAKAMI, A. E.; BARRIVIERA, V. A.; SCAPINELLO, C. Efeito da temperatura e do período de armazenamento sobre a qualidade interna do ovo de codorna japonesa para consumo humano. Revista Unimar, Maringá, v.16, p. 1325,1994.

NOGUEIRA NETO, P. Vida e criação das abelhas indígenas sem ferrão. Editora Nogueirapis, São Paulo, 1997.

OLIVEIRA, B. L. Processamento e industrialização de ovos. In: SIMPÓSIO GOIANO DE AVICULTURA, 4., 2000, Goiânia, Anais... Goiânia, Associação Goiana de Avicultura, 2000. p. 177-186.

ÖZDEMIR, A. E.; ÇANDIR, E. E.; KAPLANKIRAN, $M_{\text {; }}$ S SOYLU, E. M.; SAHINLER, N.; GÜL, A. The effects of ethanol-dissolved propolis on the storage of grapefruit cv. Star ruby. Turkish Journal of Agriculture and Forestry, v. 34, p. 155-162, 2010.

PÁDUA, J. T.; DEUS, H. A. S. B. Influência da conservação e do período de armazenamento sobre a qualidade interna e da casca de ovos comerciais.

Revista Brasileira de Ciência Avícola, Campinas, Supl. 5, p.100, 2003.

PASCOAL, L. A. F.; BENTO JUNIOR, F. A.; SANTOS, W. S.; SILVA, R. S.; DOURADO, L. R. B.; BEZERRA, A. P. A. Qualidade de ovos comercializados em diferentes estabelecimentos na cidade de Imperatriz-MA. Revista Brasileira de Saúde Produção Animal, v. 9, n. 1, p. 150-157, 2008.
RAYBAUDI-MASSILIA, R.M.; MOSQUEDAMELGAR, J., SOBRINOL'OPEZ, A.; SOLIVAFORTUNY, R.; MART'IN-BELLOSO, O. Shelf-life extension of fresh-cut "Fuji" apples at different ripeness stages using natural substances. Postharvest Biology and Technology, v. 45, p. 265-275, 2007.

SANTOS, M. S. V.; ESPÍNDOLA, G. B.; LÔBO, R. N. B.; FREITAS, E. R.; GUERRA, J. L. L.; SANTOS, A. B. E. Efeito da temperatura e estocagem em ovos. Ciência e Tecnologia de Alimentos, v. 29, n. 3, p. 513-517, 2009.

SCOTT, T. A.; SILVERSIDES, F. G. The effect of storage and strain of hen on egg quality. Poultry Science, Champaign, v. 79, p. 1725-1729, 2000.

SFACIOTTE, R. A. P. et al. Efeito do período de armazenamento, local e tipo de tratamento sobre a qualidade de ovos brancos para consumo humano. PUBVET, Londrina, v. 8, n. 19, v. 268, n. 1782, out., 2014.

SILVA, A. L. S.; BROLEZE, L. F.; SIDOU, L. F.; HENRIQUES, C. Y. H.; SPANOL, T. M.; AUGUSTO, P. E. D. Qualidade de ovos recobertos com fécula de mandioca. Tecnologia \& Ciência Agropecuária, João Pessoa, v. 4, n. 3, p. 43-46, 2010a.

SILVA, A. L. S.; BROLEZE, L. F.; SIDOU, L. F.; HENRIQUES, C. Y. H.; SPANOL, T. M.; AUGUSTO, P. E. D. Qualidade de ovos recobertos com fécula de mandioca. Tecnologia \& Ciência Agropecuária, Joao Pessoa, v. 4, n. 3, p. 43-46, 2010b. 
SOUZA, A. C. S.; PEREIRA, M. S.; RODRIGUES, M. A.V. Descontaminação prévia de materiais médico cirúrgicos: estudo da eficácia de desinfetantes químicos e água e sabão. Revista Latinoamericana Enfermagem, v. 6, p. 95-105, 1998.

SOUZA, H. B. A.; SOUZA P. A. Efeito da temperatura de estocagem sobre a qualidade interna de ovos de codorna armazenados durante 21 dias. Revista Alimentos e Nutrição, v. 6, p. 7-13, 1995.

SOUZA-SOARES, L. A.; SIEWERDT, F. Aves e ovos. Pelotas: Editora da Universidade UFPEL, 2005.

STADELMAN, W. J. The preservation of quality in shell eggs. In: STADELMAN, W. J.; COTTERILL, O. J. (Ed.). Egg science and technology.4 Th ed. Westport, Conn.: AVI Publishing, 1995. p. 67-79.

STADELMAN, W. J.; COTTERILL, O. J. Egg science and technology. New York/London: Food Products Press, 1995. 323p.

USDA - United States Department of Agriculture. Egg-grading manual. Disponível em: http://www.ams.usda.gov/poultry.

Acesso em: 28/01/2017.

WAIMALEONGORA-EK, P.; GARCIA, K. M.; NO, H. K.; PRINYAWIWATKUL, W.; INGRAM, D. R. Selected quality and shelf life of eggs coated with mineral oil with different viscosities. Journal of Food Science, Chicago, v. 74, n. 9, p. S423-S429, 2009.
WONG, Y. C.; HERALDS, T. J.; HACHMEISTER, K. A. Evaluation of mechanical and barrier properties of protein coatings on shell eggs. Poultry Science, Savoy, v. 75, n. 3, p. 417-422, 1996.

XAVIER, I. M. C.; CANÇADO, S. V.; FIGUERERO, T. C.; LARA, L. J. C.; LANA, A. M. Q.; SOUZA, M. R.; BAIÃO, N. C. Qualidade de ovos de consumo submetidos a diferentes condições de armazenamento. Arquivos Brasileiros de Medicina Veterinária e Zootecnia, Belo Horizonte, v. 60, n. 4, p. 953-959, 2008. 